\title{
Prototype Design and Analysis of Miniature Pulse Discharge Current Generator on Various Burdens
}

\author{
Waluyo, Syahrial, Sigit Nugraha, and Yudhi Permana JR \\ Department of Electrical Engineering \\ Institut Teknologi Nasional (Itenas), Bandung, Indonesia \\ waluyo@itenas.ac.id
}

\begin{abstract}
High voltage impulse is one of the means used in a variety of insulating materials testing. It causes also discharge, generally as visualization of lightning strikes. This research aimed to design a prototype of miniature current discharge pulse generation with various burdens. The alternating low voltage was rectified first and multiplied by using the modified Cockroft-Walton voltage multiplier. The yielded output voltage was a d.c. high voltage, which subsequently entered the pulse generator circuit, penetrating the sphere gap, after filling the charge on the first capacitor and then fill in the second capacitor. The shape of the output pulse current was tapped by using a resistive voltage divider. Thus, the various pulse current waveforms could be measured and recorded by a storage digital oscilloscope.

Almost first discharge were occurred in around from $1 \mu \mathrm{s}$ to $2 \mu \mathrm{s}$. The waveforms with the pure resistive burdens would trend to be symmetrical to almost on positive parts. On the other hand, the waveforms with the resistive and capacitive dominated burdens would be shorter, i.e. around $16.8 \mu \mathrm{s}$, than those resistive dominated burdens. The wave frequency response of discharge on the capacitive dominated burdens would more declivous or prevalent than those on the resistive dominated burdens. The latter characteristics were indicated by the specific capacitive dominated property. The capacitive property that store charge was expected as cause the latter characteristics. The dominated capacitive existence made the repetitive discharge would be shorter than those the dominated resistive existence.
\end{abstract}

Keywords: miniature, pulse, discharge, current, burden

\section{Introduction}

An impulse voltage is a unidirectional voltage, which generally without appreciable oscillation, rises rapidly to a maximum value and falls more or less rapidly to zero value. Small oscillations are tolerated, provided that their amplitudes are less than $5 \%$ of the peak values. If the impulse voltage develops without causing flashover of puncture occur, it is called a chopped impulse voltage. A full impulse voltage is characterized by its peak value and its two time interval $[1,2]$.

The actual shape of both kinds of lightning and switching over voltages varies strongly. Nevertheless, it became necessary to simulate these transient voltages by relatively simple means for testing purposes. The various standards define the impulse voltages as a unidirectional voltage which rises more or less rapidly to a peak value and the decays relatively slowly to zero. Impulse voltages with front durations varying from less than one up to a few tens of microseconds are considered as lightning impulse generally. Lightning impulses are very short duration, mainly if they are chopped on front [3].

Transient over voltages due to lightning and switching surges cause steep build-up of voltage on transmission lines and other electrical apparatus. The experimental investigations showed that these waves have a rise time of 0.5 to $10 \mu$ s and decay time to $50 \%$ of the peak value of the order 30 to $200 \mu \mathrm{s}$. The wave shapes are arbitrary, but mostly unidirectional. It is shown that lightning overvoltage wave can be represented as double exponential waves defined by the equation (1).

Received: August $30^{\text {th }}, 2015$. Accepted: September $25^{\text {th }}, 2016$

DOI: 10.15676/ijeei.2016.8.3.2 


$$
V=V_{o}\left[e^{-\alpha t}-e^{-\beta t}\right]
$$

where $\alpha$ and $\beta$ are constants of microsecond values. This equation represents a unidirectional wave which usually has a rapid rise to the peak value and slowly falls to zero value [4].

A simple, approximate mathematical expression for $8 / 20 \mu$ s short circuit current waveform that is specified in the standards is $\mathrm{I}(\mathrm{t})$, as given by equation (2).

$$
I(t)=A I_{p} t^{3} e^{\left(-\frac{t}{\tau}\right)}
$$

Nevertheless, for current impulses on his research results, the delay time, rise time and full width at half-maximum values were $16.2 \mu \mathrm{s}, 8.02 \mu$ s and $20.7 \mu$ s respectively [5].

The electrical strength of high voltage apparatus against external over voltages that can appear in power supply systems due to lightning strokes is tested with lightning impulse voltages. The rising part of the impulse voltage is referred to as the front, the maximum as the peak and the decreasing part as the tail. The waveforms can be represented approximately by supervision of two exponential functions with differing time constants [6]. The standard lighting impulse is described as a $1.2 / 50 \mu$ s wave, and the standard switching impulse is a 250/2500 $\mu$ s wave [7].

A development of Matlab Simulink model has been carried out for the experimental setup above. The results of the investigation showed that it was very efficient in the learning effect of changes in the design parameters to obtain the impulse voltage and the desired waveform of the impulse voltage generator for high voltage applications [8].

It has been conducted a series of simulations to adjust the formation of the output of a kind type of Marx impulse generator. The goal was to estimate the leak capacitance and capacitance insert into circuit simulation to effectively produce an output that was similar to the generator. An actual three-stage impulse generator, with several different levels of impulse voltage test and the recorded output waveform, was used as a basis. The research was carried out to formulate the capacitance leak and identifying the location of capacitance in the generator. The research showed that an effective simulation of the circuit could be created to provide output as close as possible [9].

It has been made the development of Marx generator type vertical structure twenty steps. In a matching load of 90-100, it has been obtained for $25 \mathrm{kV}$ DC discharge, a pulse output voltage $230 \mathrm{kV}$, and a duration of $150 \mathrm{~ns}$. This voltage pulse was applied to a relativistic electron beam planar diode. For a cathode-anode gap of $7.5 \mathrm{~mm}$, it has been obtained an REB had shot 160 $\mathrm{kV}$ voltage and duration of $150 \mathrm{~ns}$ [10].

It has been developed an impulse generator circuit using OrCAD PSpice software to generate a waveform lightning according to IEC61000-4-5 standard. For this purpose, it has been used as Marx generator main principles of design with a few modifications to the parameters and components. The waveform output of the simulation compared to the surge as IEC61000-4-5 standards, and the values in the series developed arranged so that the characteristics of the waveform in the limits of the acceptable. As a result, the true lightning waveforms in the form of voltage versus time were raised from an impulse generator circuit [11].

It has been described how to calculate constant impulse voltage generator circuit with the impulse voltage was given. From the results, it appeared that the effect of the revision of the definition depended on the circuit constants [12].

It has been done the design, construction and analysis of the uncertainty of impulse voltage calibrator that could be calculated. The calibrator was as the primary reference for the measurement of impulse voltage. It generated impulse voltage with the peak, front and tail values were known. The peak voltage range was constructed from $50 \mathrm{mV}$ to $1000 \mathrm{~V}$ [13]. 
The electrical characteristics and description of low inductance design, compact, $500 \mathrm{kV}$, $500 \mathrm{~A}, 10 \mathrm{~Hz}$ repetition rate, Marx generator for generating a high-power microwave source or high power microwave (HPM) has been presented. This included the analysis of relevant background of the Marx generator and HPM source [14].

The trigger pulses of high voltage were required for initial conduction in a triggered spark gap that require a high impedance voltage source. This work illustrated the design, construction and operation of two high-voltage pulse generator and a spark gap [15].

It has been presented the parameter optimization technology for the generation of lightning current waveforms for first short stroke $(10 / 350 \mu \mathrm{s})$ which was needed to test the performance of lightning protection components, as required in IEC 62305 and IEC 62561. The crowbar devices were specified in IEC 62305 that was applied to generate lightning current waveform. The results, in this experiment were the new parameters of the circuit needed to be changed because of the difference between the simulation and experimental results. An external coil type multistage and a damping resistor have been proposed to make the generation efficiency increased. According to these results, it was obtained by an optimization of the lightning current waveform first short stroke [16].

Impulse generators were implemented as digital switching circuits to utilize the fast switching speed of CMOS transistors and save power. In the single-polarity DWG prototype, the impulse generator is designed based on a glitch generator [17].

When the analytical equations were used as an impulse source, it worked as a perfect generator and output waveform characteristics were not dependent on the impedance of the system. It could be confirmed that the waveform characteristics; delay time, rise time and FWHM remain unchanged for two impedance ranges considered when used model equations as generator sources for both voltage and current impulses. It was found that as for $1.2 / 50 \mu \mathrm{s}$ voltage impulses, delay time, rise time and FWHM values were $4.95 \mu \mathrm{s}, 1.20 \mu \mathrm{s}$ and $81.8 \mu \mathrm{s}$ respectively through the tested impedance range. For $8 / 20 \mu$ s current impulses, these values were $16.2 \mu \mathrm{s}, 8.02$ and $20.7 \mu$ s respectively throughout the tested impedance range. Hence, characteristics of waveforms introduced to the system were not depending on the impedance of the system and no loading effect in action under this scenario. Thus, when the analytical equations were used as impulse sources, both voltage and current source models were performed as ideal generators. Obviously, the waveform characteristics of the generated impulses were varied by the influence of the nonlinear load impedance. These results implies that the impedance of the system load be able to influence the generator characteristics. When impedance of the nonlinear load increased, the characteristics of current impulse waveform were also changed and significantly deviated from the expected values. However, when the impedance was at its lowest value, these parametric values were almost equal to the values obtained when the analytical equation was used as current impulse source. When impedance of the nonlinear load decreased, the characteristics of voltage impulse waveform were also deviated from the expected values. However, when the impedance was at its highest value, these parametric values were almost equal to the values obtained when the analytical equation was used as voltage impulse source. When the analytical equations were used as impulse sources it worked as perfect generators and V-I characteristics were not depend on the impedance of the system. However, V-I characteristics of the generated waveforms are varied significantly by the impedance of the nonlinear load that was connected to the generator circuit models. The deviations were due to influence caused by the nonlinear load to the generator circuit parameters and effective internal impedance [5].

From some of the literature reviews, it is necessary for development in terms of the formation of the prototype, namely in the form of utilization of high voltage generation in line with the full-wave rectifier and utilization of high voltage multiplier results to be used as a source of impulse voltage generation. This research was to design and implement the prototype miniature of impulse high voltage generator based on the results of high voltage d.c. multiplier generator. 
The state of the art in this research was a pulse current generation in the miniature prototype, where the sphere gap distance was also very short, around $1.5 \mathrm{~mm}$, and the currents were recorded in various burden scenarios. Thus, the phenomena of current pulse waveforms could be understand in various burdens. For one period, these waveforms were similar to an electrostatic discharge current. However, due to the source was direct current (dc), not a capacitor only, the breakdown discharges were occurred in many times, instead of once. To get some waveform phenomena, it was carried out to give four scenarios to the circuits. The recording system was used the digital storage oscilloscope. The data could be opened, analyzed and made curves by Excel. The data could also be made FFT analyses by using OriginPro. Thus, the trending curves and the frequency spectra could be investigated.

Compared to the previous researches, usually, they were simulation works only, so that not considered the distance of sphere gap, or the measurement methods those done were voltage quantity, instead of current. Therefore, in this research, it was recorded the discharge currents practically or in real conditions. At the analyses, the frequency responses of discharge current waveforms were presented also. Thus, the frequency domains would be analyzed too.

\section{Research Methods}

This research was the continuation from the previous one [18]. Nevertheless, it emphasized the miniature sphere gap pulse phenomena due to d.c. high voltages. The block diagram for this circuit design is shown in Figure 1.

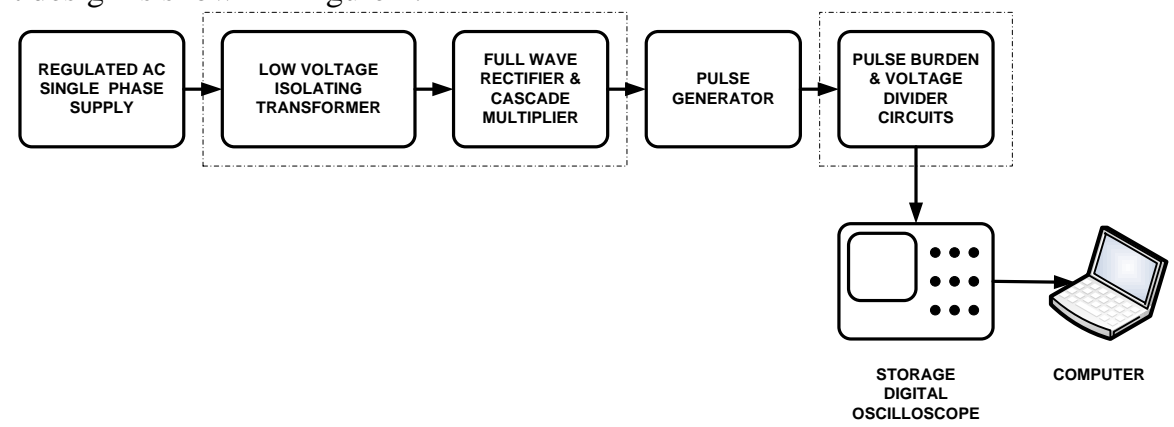

Figure 1. Blok diagram of pulse generator and measurement

From the single phase supply, the electric source entered to the insulating transformer, which isolated the main circuit from power source. The low a.c. voltage was rectified and multiplied by the cascade circuit. For this case, the secondary voltage of transformer was rectified and muliplied by the cascade multiplier circuit. Therefore, it was yielded the d.c. high voltages. The d.c. high voltages were subjected to the air sphere gap, with the gap distances were 1-2 $\mathrm{mm}$ in range. Depending upon the d.c. high voltage magnitudes, the air gap between the metal spheres would be breakdown or discharge. There was also the circuit after the metal spheres, namely the pulse burden and voltage divider circuits. The pulse burden circuit was mainly functioned as a current limiter of the discharge current. Therefore, the d.c. cascade circuit would be relatively safe when the metal sphere gap was breakdown. Otherwise, the voltage divider circuit was mainly functioned as measurement purpose, that connected to the storage digital oscilloscope and ultimately connected to the computer. It enable also that the pulse burden circuit was at once as a voltage divider circuit. The measured data were recorded by the computer and could be saved in softcopy forms for further analysis.

Figure 2 shows a simulation circuit of typical impulse burden. There were the resistors, the voltage divider resistors and the capacitors. The voltage divider was for tapping the occurred voltage, and as the input voltage to the channel of the storage digital oscilloscope. However, the measured quantities were the pulse currents. Thus, the real electric current that flow in the pulse burden circuit was as in equation (3). 


$$
I=\frac{V}{R}
$$

where $\mathrm{V}$ as the real occurred voltage that measured by the oscilloscope and $\mathrm{R}$ was the tapping resistor.

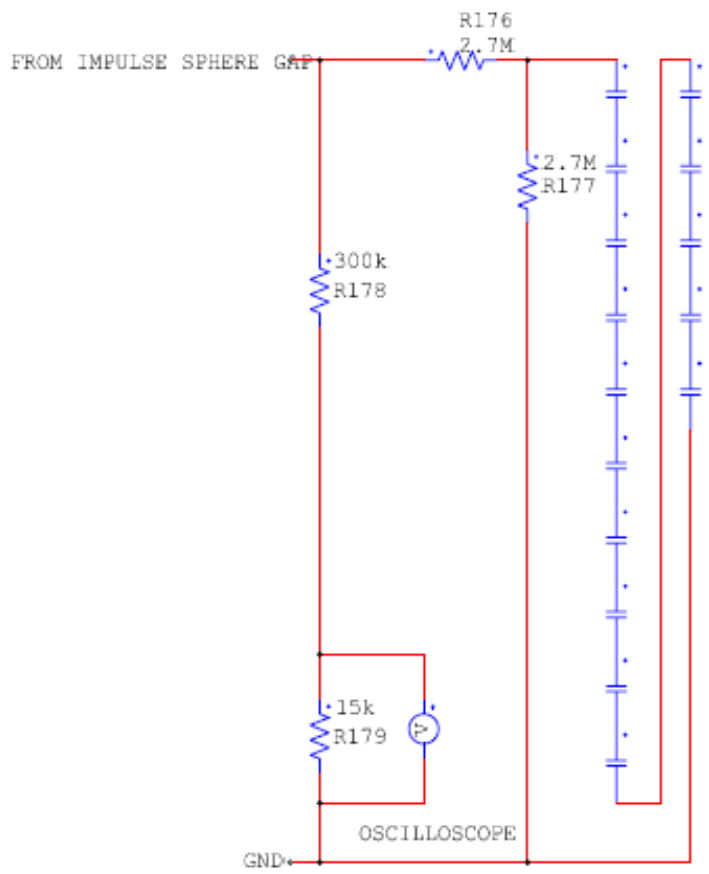

Figure 2. The typical of impulse burden

In assembling of the impulse generation, the main component consisted of transformer diodes, capacitors and resistors. The transformer which used was as step-up transformer, and as insulation transformer, 500 watt, 0.5 ampere. The diode role was very important, where the working principle of the diode is only issued once of the flow, either positive or negative depending on the purposes of the output. In this assembly, it was used the diodes of 25F120/1322 type. The used capacitors were direct current with type of PAG/450Volt-100 $\mathrm{FF}$ and the resistors were used ceramic type.

The necessary measured quantity was discharge current. However, the oscilloscope could not measure the current quantity, instead of voltage quantity. Nevertheless, the discharge current could be measured by the oscilloscope through series voltage divider resistors. Thus, the discharge current phenomena could be measured indirectly and the measuring equipment was in safe conditions. The measurements were carried out in many times. Nevertheless, they are presented in several results only. They were typical results according to the burden categories.

\section{Research Results And Discussion}

Figure 3 shows the complete assembly of research, including the sphere gap electrodes for impulse generation that have been formed. It is seen that the input of the circuit, such as transformer, to the output circuit, a series of impulse generation, including the sphere gap electrode, capacitor and resistor circuits. Besides that, there were two voltmeters for voltage measuring purposes. 
Waluyo, et al.

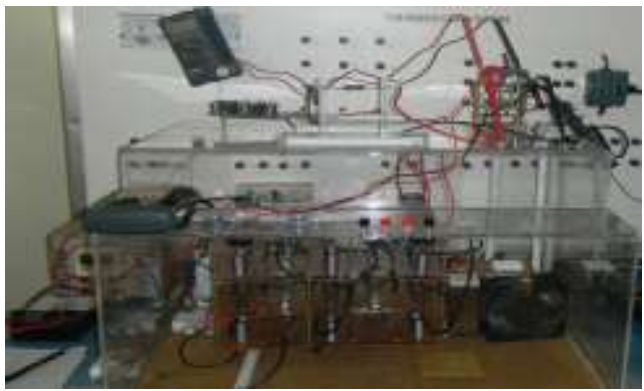

Figure 3. The complete set of pulse generation

Figure 4 shows the miniature sphere gap for pulse generation. The distance of the sphere gap could be adjusted. Nevertheless, in this research, it was typically $0.5-2.0 \mathrm{~mm}$ in range.

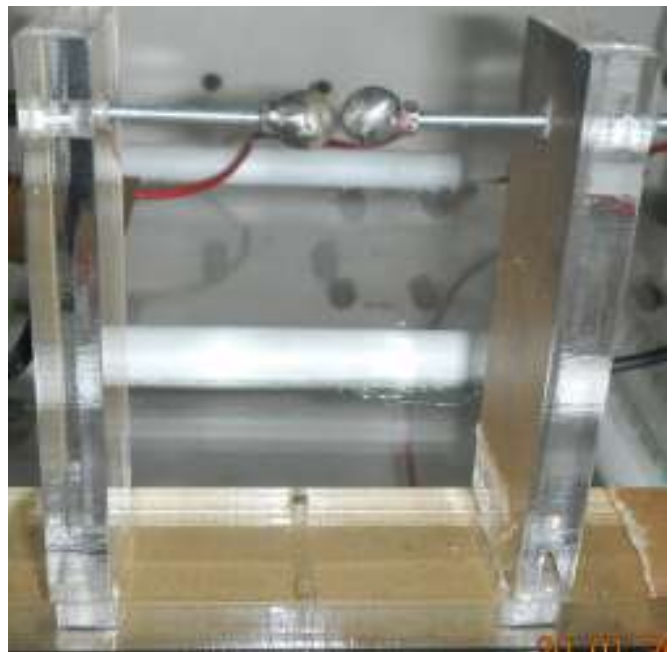

Figure 4. The sphere gap electrodes for impulse generation

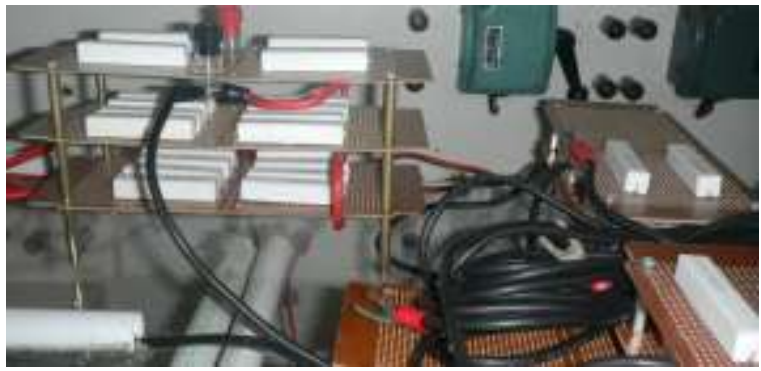

(a) Resistor circuit

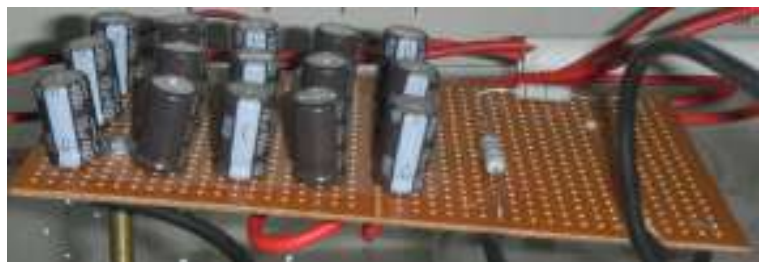

(b) Capacitor circuit

Figure 5. The resistor and capacitor burden circuits of pulse generation 
Figure 5(a) shows the resistors pulse burden and voltage divider circuits, whereas Figure 5(b) shows the capacitors for pulse burden circuits. Both circuits would be used as burdens of pulse generation.

Figure 6 shows the complete set of the pulse current generator, including the measuring devices. First device was a variac, which regulated the input voltage magnitude. Consequently, the dc output voltage that made the pulses would increase too. Furthermore, the electric power entered to the transformer, which the main function was as a insulating circuit, beside as a stepup of voltage. The insulating transformer isolated the circuit between the panel power supply and the main circuit of cascade dc voltage multiplier. The next step was the cascade dc voltage multiplier, which could increase a medium voltage in several kilo volts. After reached the medium voltage, it injected the pulse burdens through the sphere gap electrodes. The pulse burdens consisted of the resistors and capacitors. Some resistors also functioned as a voltage divider, which the small voltage was measured by the oscilloscope.

The data, which were measured by the digital storage oscilloscope, were transferred to the computer. The recorded data were in both bitmap (bmp) and comma separated values (csv) file forms. Thus, based on the csv files, the recorded data could be further analyzed.

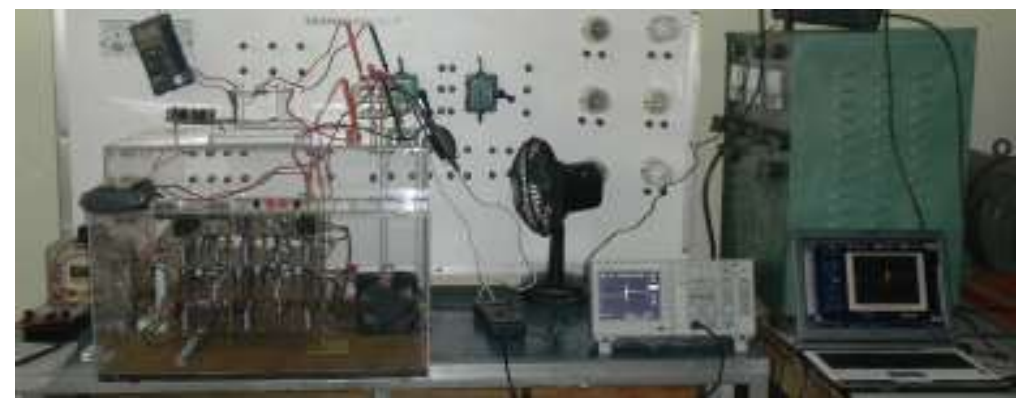

Figure 6. The complete circuit of impulse generation and measurement system

Figure 7 shows an example of original bitmap (bmp) picture form of recorded data. It shows the division for voltage (vertical magnitude) and time (horizontal), date and time of measurements, waveforms, acquire, and so on. The picture was also for crosscheck the analyzed data that done by Microsoft excel and other program software. However, on the capture bmp picture, the starting point of time parameter was zero value, that was the central point of horizontal axis.

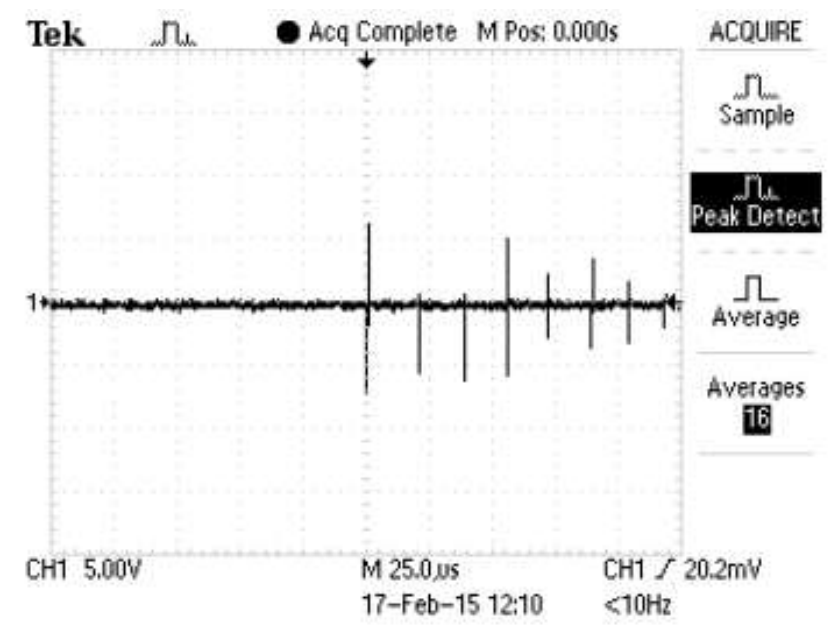

Figure 7. An example of original bmp form of recorded data 
Figure 8 presents the first scenario of pulse burden circuits. In this circuit, it was pure resistive burden that parallel two $2.7 \mathrm{M} \Omega$ and $300 \mathrm{k} \Omega$ resistors. The measured voltage was tapped on the $15 \mathrm{k} \Omega$ resistor, which was the input of the oscilloscope.

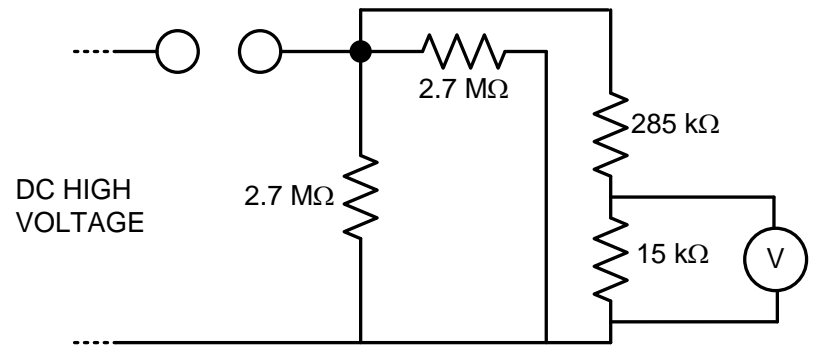

Figure 8. First scenario of pulse burden as short pure resistive circuit

Figure 9 shows the first sample current waveform of measurement result for the first scenario of pulse burden circuit. Figure 9(a) is the first single waveform of discharge pulse. In this waveform, the discharge pulse was occurred in time of $1 \mu \mathrm{s}$, and the specific discharge wave would cease in time of around $2 \mu \mathrm{s}$. Figure 9 (b) is the multiple waveform of discharge pulse. The discharge pulses were occurred in time of 31, 51, 67, 86, 101 and $116 \mu$ s, after the first pulse. The average different time among pulses was $17 \mu \mathrm{s}$. Figure 9(c) is the short range of frequency response. The magnitude would increase locally in frequency of 34180, 43945 and $61035 \mathrm{~Hz}$, and Figure 9(d) is the long range one. Generally, the magnitudes of discharge current would decrease as the frequency increased slightly.

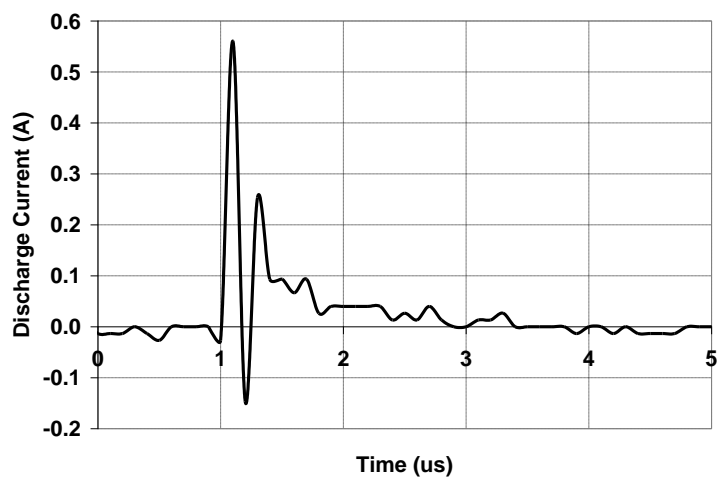

(a) First single waveform

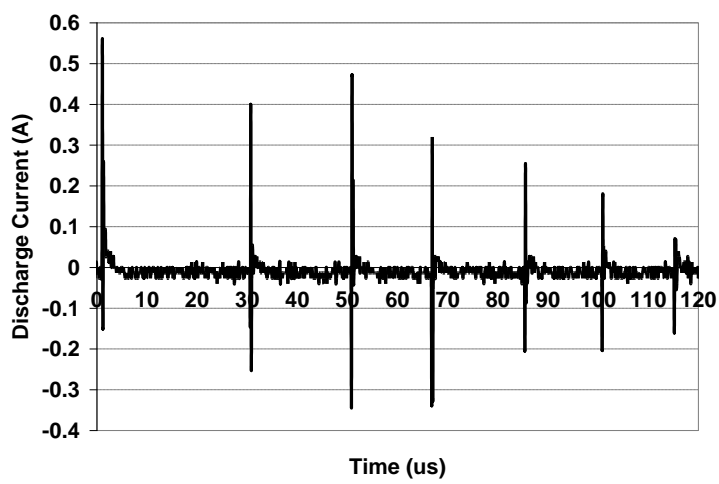

(b) Multiple waveform 


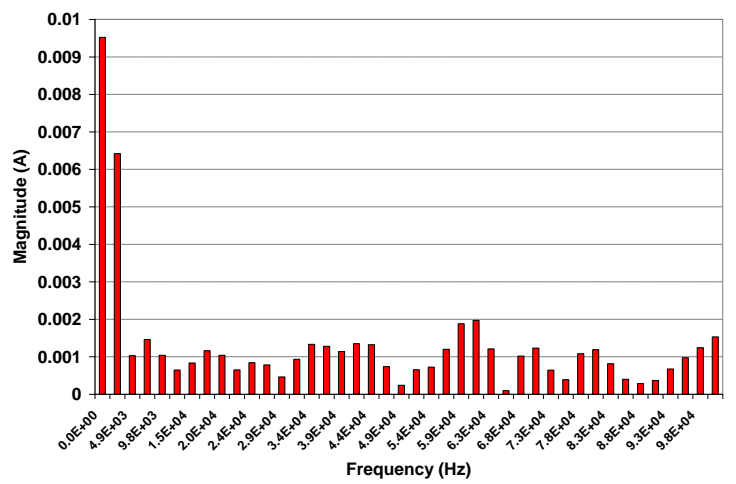

(c) Short range of frequency response

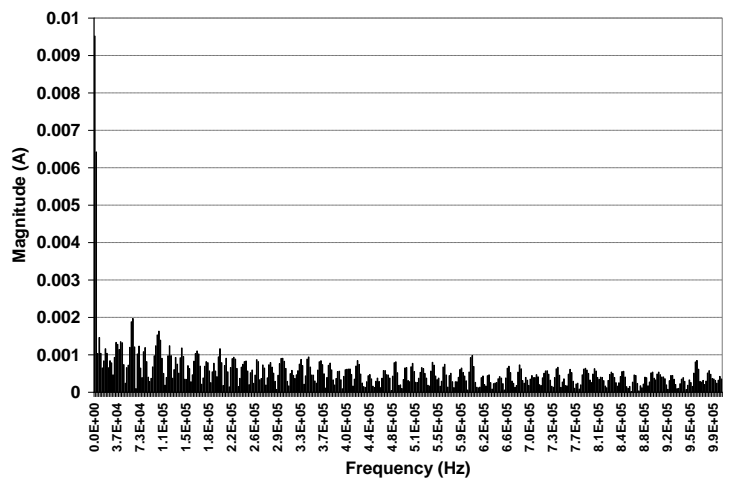

(d) Long range of frequency response

Figure 9. First sample current waveform result for the first scenario of pulse burden circuit

Figure 10 shows the second sample current waveform of measurement result for the first scenario of pulse burden circuit. Figure 10(a) is the first single waveform of discharge pulse. In this waveform, the discharge pulse was occurred in time of around $1 \mu \mathrm{s}$, and the specific discharge wave would cease in time of around $2 \mu \mathrm{s}$. Figure 10(b) is the multiple waveform of discharge pulse. In this waveform, the discharge pulses were occurred in time of $26,45,66,83$, 98 and $111 \mu \mathrm{s}$, after the first pulse. The average different time among pulses was $17 \mu$ s. Figure 10 (c) is the short range of frequency response. The magnitude would increase locally in frequency of 31738, 48828 and $61035 \mathrm{~Hz}$, and Figure 10(d) is the long range one, where the magnitudes of discharge current would decrease slightly as the frequency increased.

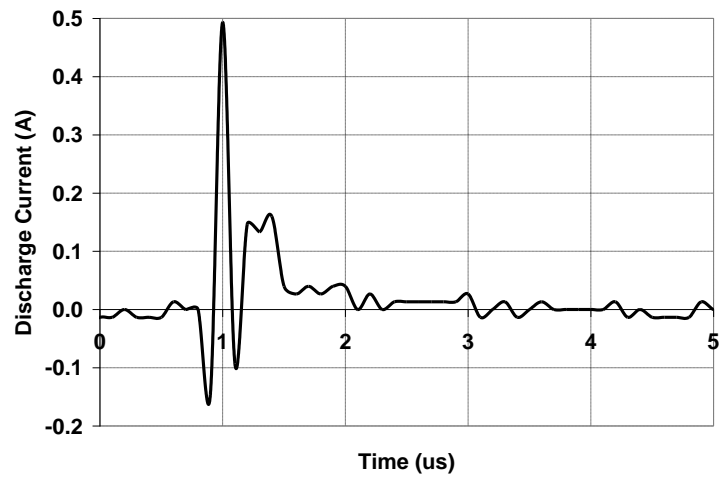

(a) First single waveform 
Waluyo, et al.

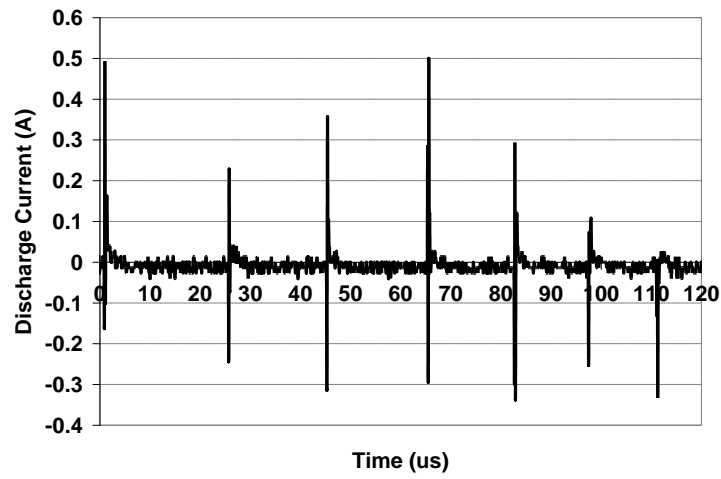

(b) Multiple waveform

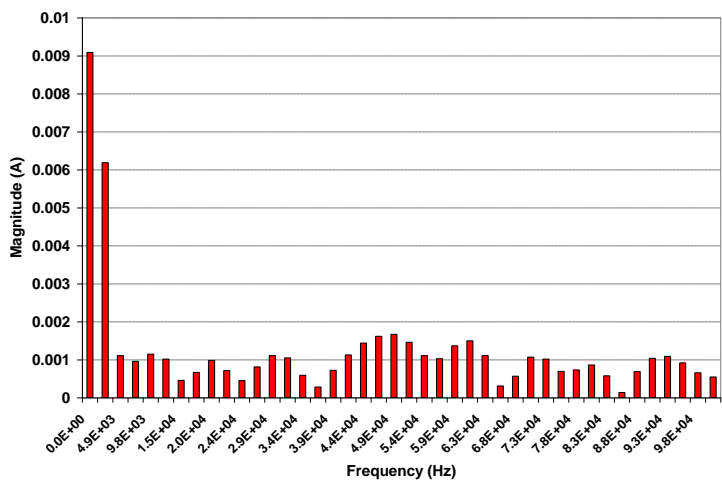

(c) Short range of frequency response

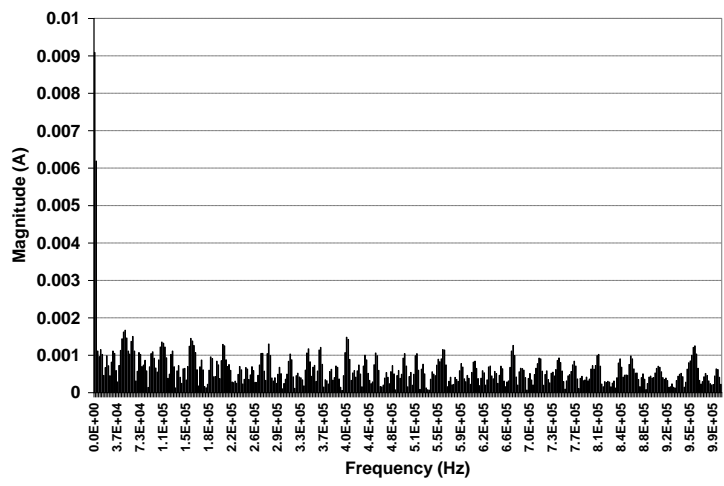

(d) Long range of frequency response

Figure 10. Second sample current waveform result for the first scenario of pulse burden circuit

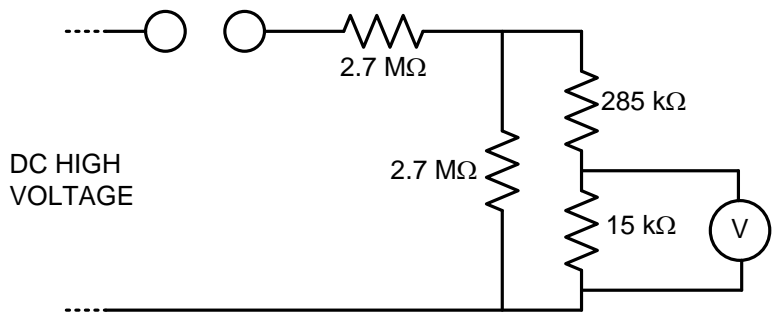

Figure 11. Second scenario of pulse burden as long pure resistive circuit 
Figure 11 shows the second scenario of pulse burden circuits. In this circuit, it was pure resistive burden that parallel an $2.7 \mathrm{M} \Omega$ and $300 \mathrm{k} \Omega$ resistors, and in series with resistor of 2.7 $\mathrm{M} \Omega$.

Figure 12 shows the first sample current waveform of measurement result for the second scenario of pulse burden circuit. Figure 12(a) is the first single waveform of discharge pulse. In this waveform, the discharge pulse was occurred in time of around $1 \mu \mathrm{s}$, and the specific discharge wave would cease in time of around $2 \mu \mathrm{s}$. Figure 12(b) is the multiple waveform of discharge pulse. In this waveform, the discharge pulses were occurred in time of 30, 54, 74, 92 and $111 \mu \mathrm{s}$, after the first pulse. The average different time among pulses was $20 \mu \mathrm{s}$. Figure 12 (c) is the short range of frequency response. The magnitude would increase locally in frequency of 26855, 36621 and $53711 \mathrm{~Hz}$, and Figure 12(d) is the long range one. The magnitudes of discharge current would decrease slightly as the frequency increased.

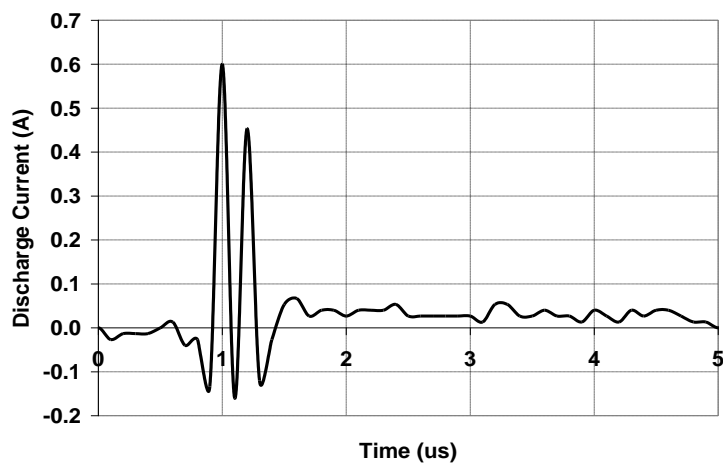

(a) First single waveform

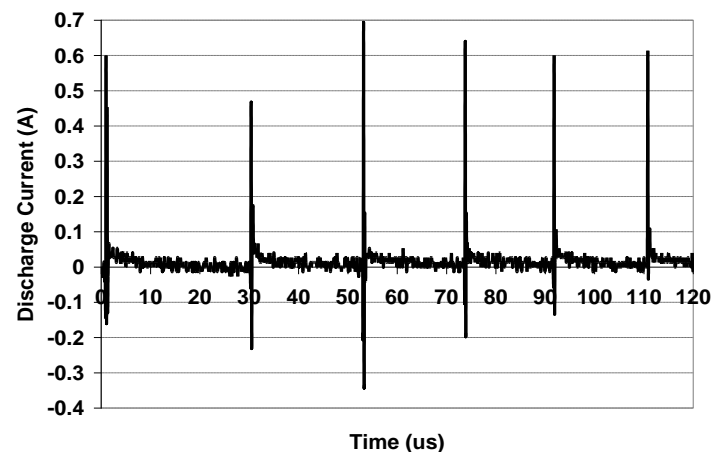

(b) Multiple waveform

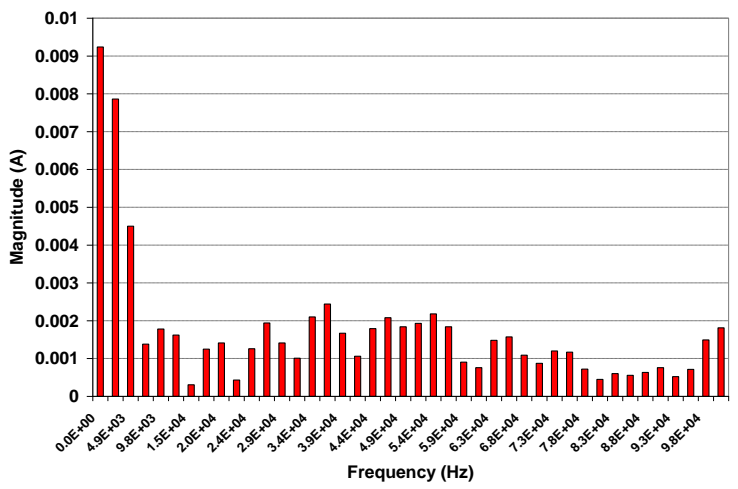

(c) Short range of frequency response 
Waluyo, et al.

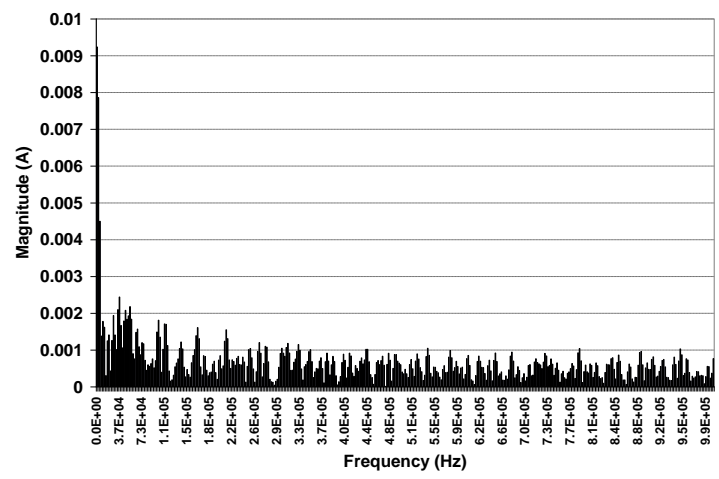

(d) Long range of frequency response

Figure 12. First sample current waveform result for the second scenario of pulse burden circuit

Figure 13 shows the second sample current waveform of measurement result for the second scenario of pulse burden circuit. Figure 13(a) is the first single waveform of discharge pulse. In this waveform, the discharge pulse was occurred in time of around $1 \mu \mathrm{s}$, and the specific discharge wave would cease in time of around $2 \mu \mathrm{s}$. Figure 13(b) is the multiple waveform of discharge pulse. In this waveform, the discharge pulses were occurred in time of 27.5, 53, 73, 94 and $112 \mu \mathrm{s}$, after the first pulse. The average different time among pulses was $22.24 \mu \mathrm{s}$. Figure 13(c) is the short range of frequency response. The magnitude would increase locally in frequency of 26855, 36621 and $46387 \mathrm{~Hz}$, and Figure 13(d) is the long range one, where the magnitudes of discharge current would decrease slightly as the frequency increased.

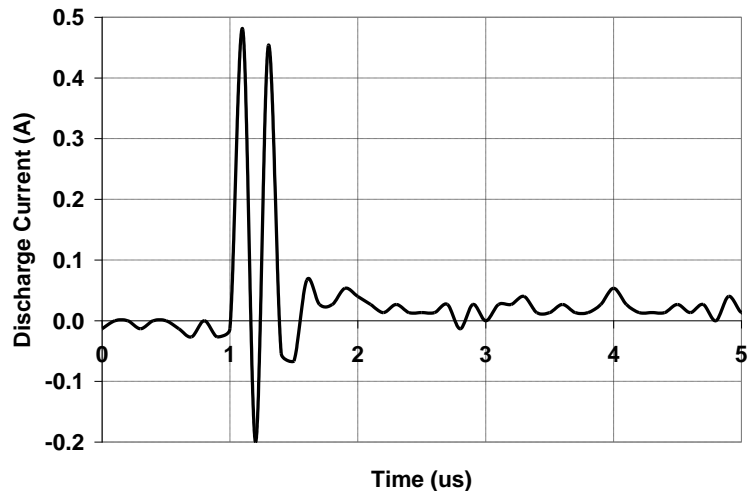

(a) First single waveform

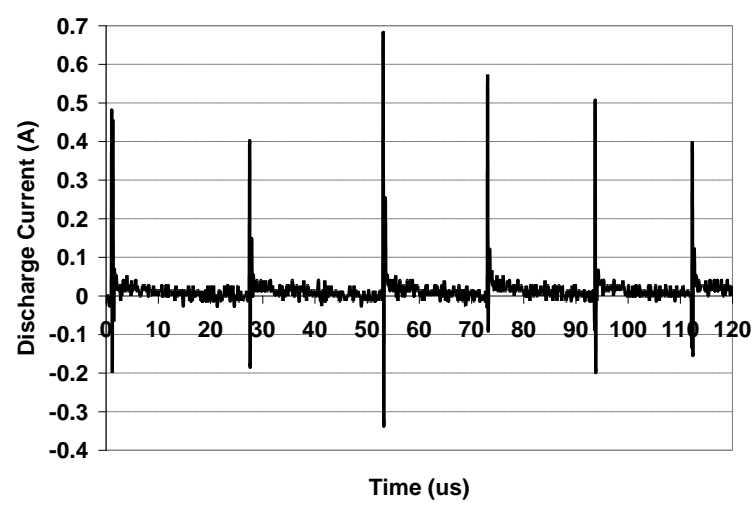

(b) Multiple waveform 


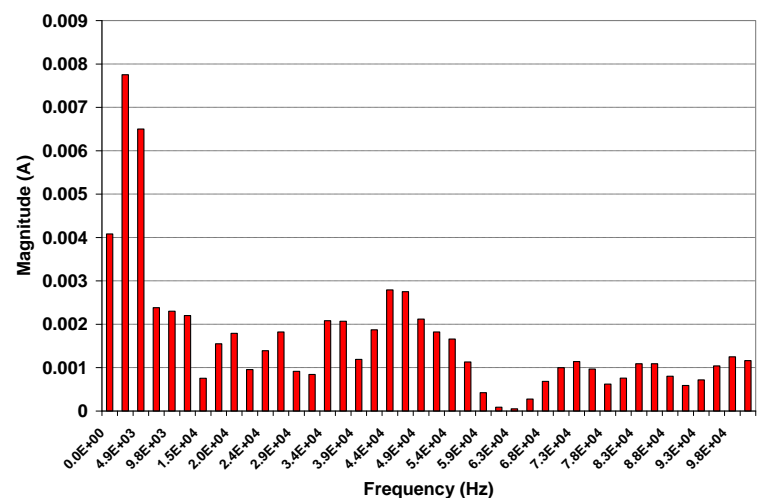

(c) Short range of frequency response

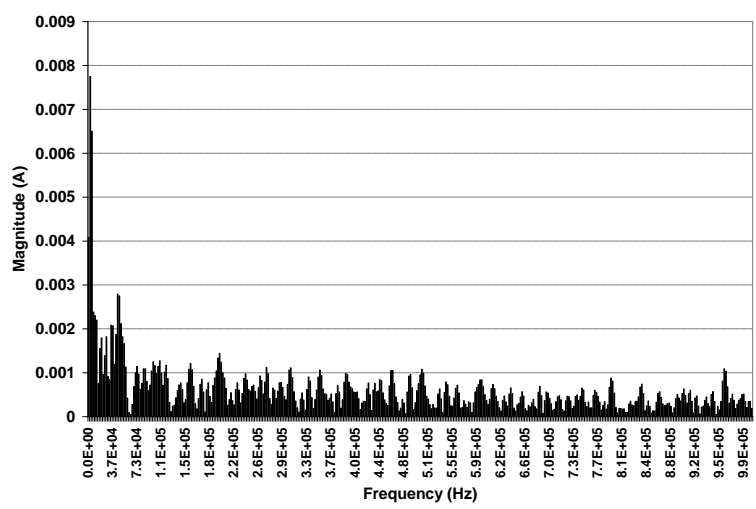

(d) Long range of frequency response

Figure 13. Second sample current waveform result for the second scenario of pulse burden circuit

Figure 14 shows the third scenario of pulse burden circuits. In this circuit, it was pure 2.7 $\mathrm{M} \Omega$ resistive burden that series with $300 \mathrm{k} \Omega$ resistor and series $15 \times 10 \mu \mathrm{F}$ in parallel. Those component were parallel connection with the resistor of $2.7 \mathrm{M} \Omega$.

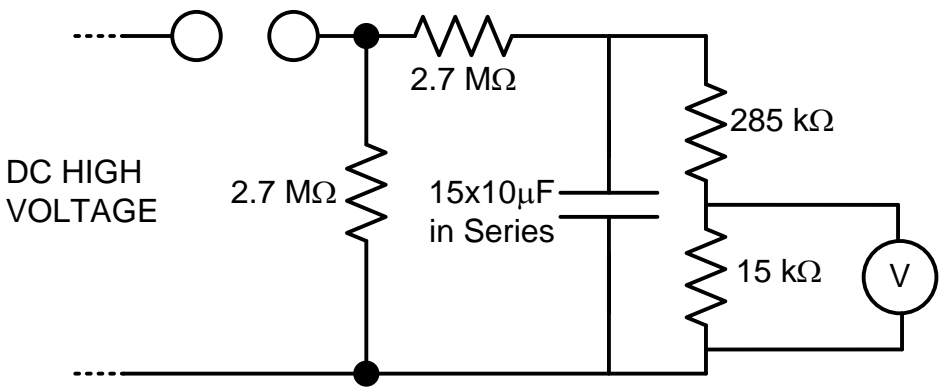

Figure 14. Third scenario of pulse burden as short capacitive-resistive circuit

Figure 15 shows the first sample current waveform of measurement result for the third scenario of pulse burden circuit. Figure 15(a) is the first single waveform of discharge pulse. In this waveform, the discharge pulse was occurred in time of around $1 \mu \mathrm{s}$, and the specific discharge wave would cease in time of around $2 \mu \mathrm{s}$. Figure 15(b) is the multiple waveform of discharge pulse. In this waveform, the discharge pulses were occurred in time of $27.5,53,73$, 
Waluyo, et al.

94 and $112 \mu \mathrm{s}$, after the first pulse. The average different time among pulses was $22.24 \mu \mathrm{s}$. Figure $15(\mathrm{c})$ is the short range of frequency response. The magnitude would increase locally in frequency of $61035 \mathrm{~Hz}$, and Figure 15(d) shows the long range one, where the magnitudes of discharge current would decrease slightly as the frequency increased.

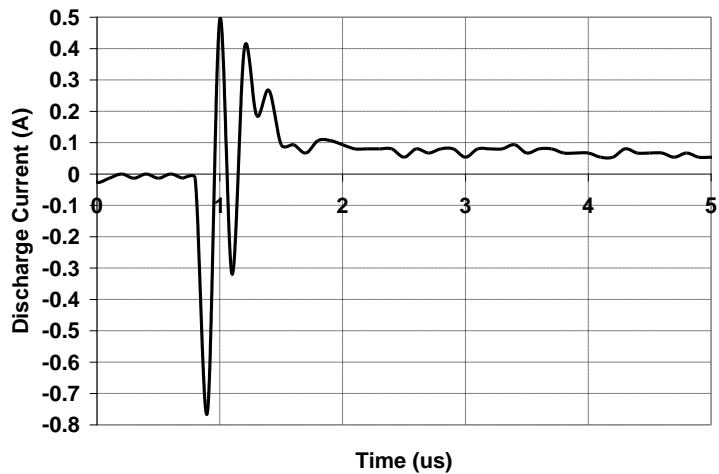

(a) First single waveform

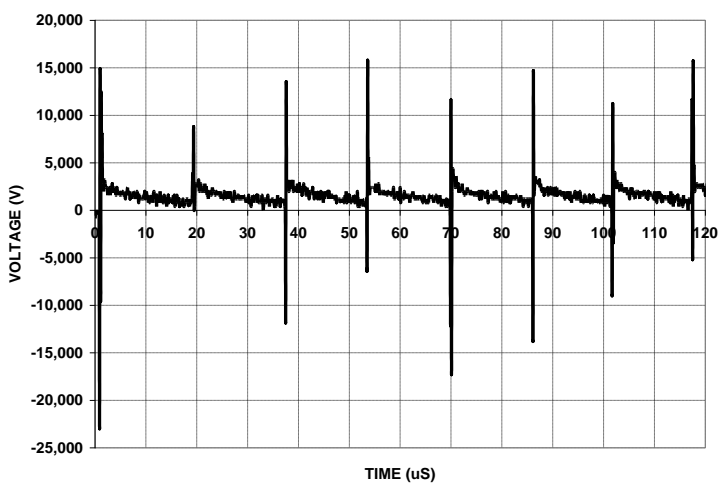

(b) Multiple waveform

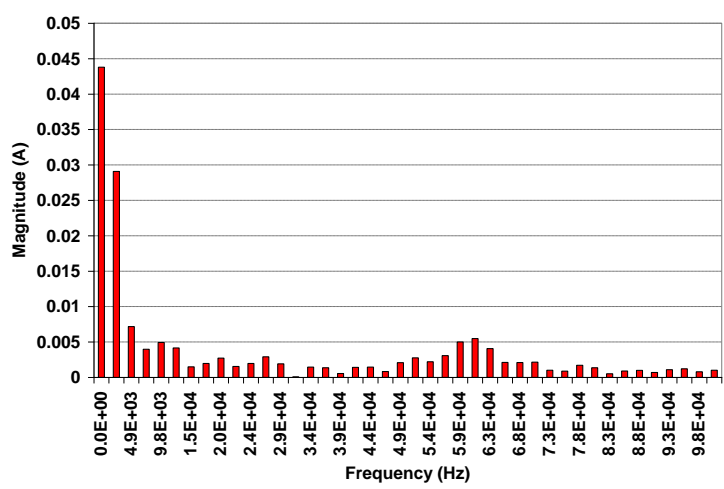

(c) Short range of frequency response 


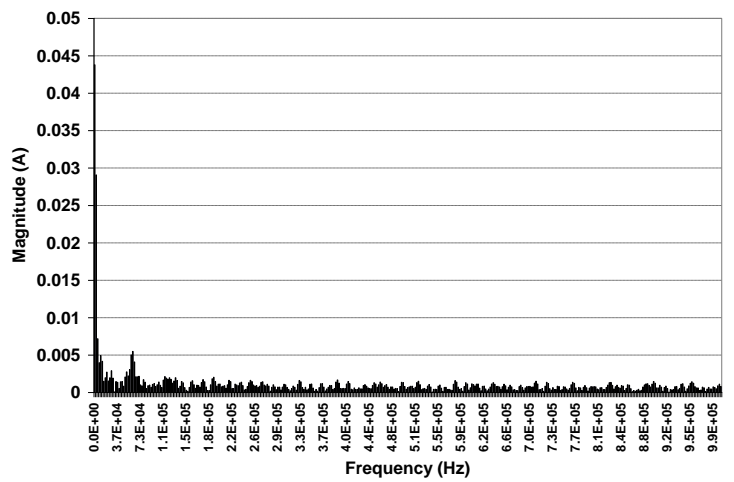

(d) Long range of frequency response

Figure 15. First sample current waveform result for the third scenario of pulse burden circuit

Figure 16 shows the second sample current waveform of measurement result for the third scenario of pulse burden circuit. Figure 16(a) is the first single waveform of discharge pulse. In this waveform, the discharge pulse was occurred in time of around $1 \mu \mathrm{s}$, and the specific discharge wave would cease in time of around $2 \mu \mathrm{s}$. Figure 16(b) is the multiple waveform of discharge pulse. In this waveform, the discharge pulses were occurred in time of 21, 43.6, 61, 81 and $107.6 \mu \mathrm{s}$, after the first pulse. The average different time among pulses was $21.32 \mu \mathrm{s}$. Figure 16(c) is the short range of frequency response. The magnitude would increase locally in frequency of 36621 and $48828 \mathrm{~Hz}$, and Figure 16(d) is the long range, that similar to the previous one.

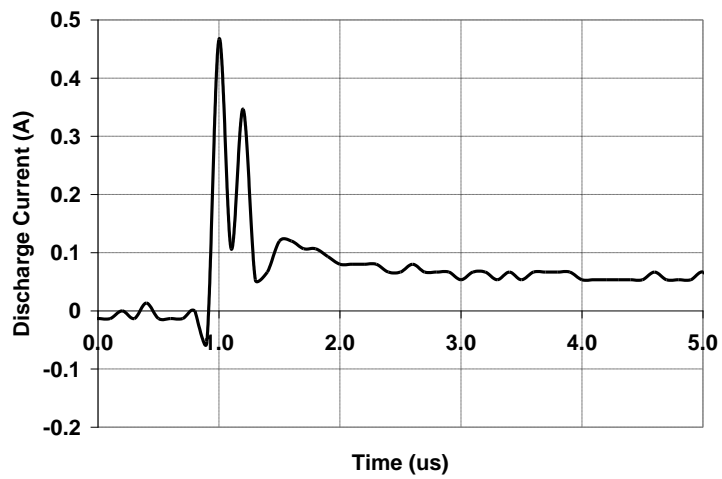

(a) First single waveform

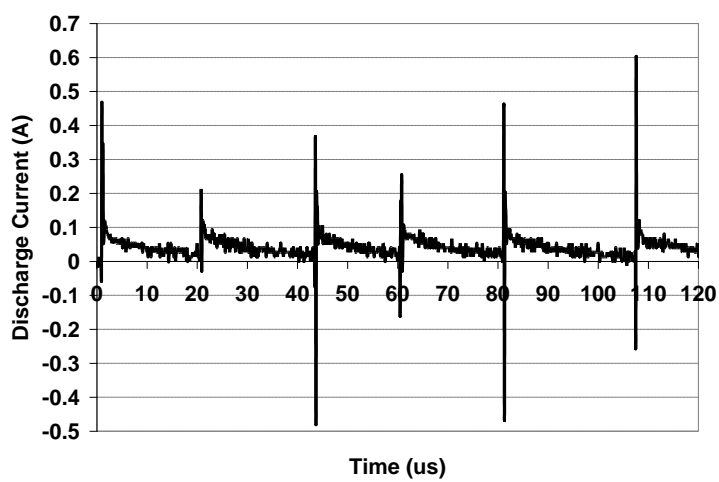

(b) Multiple waveform 


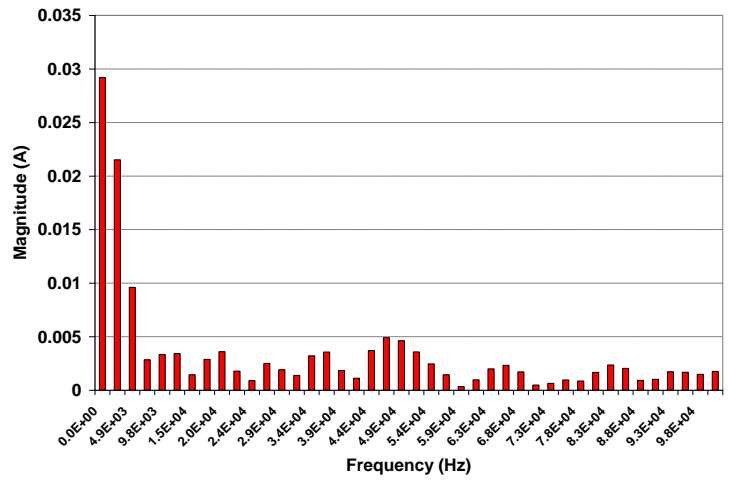

(c) Short range of frequency response

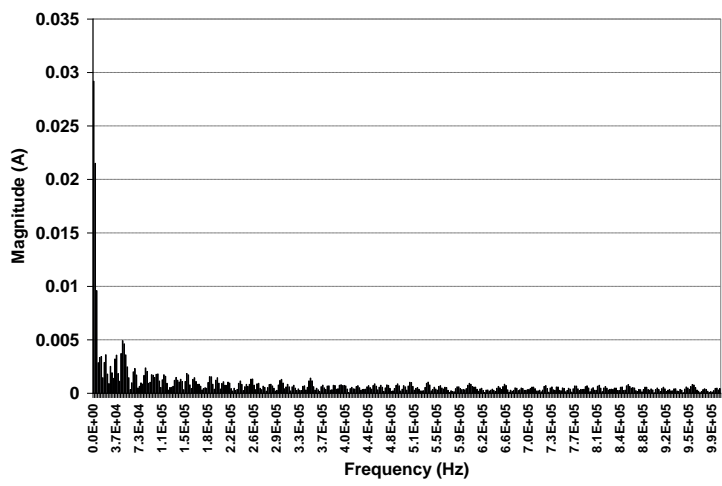

(d) Long range of frequency response

Figure 16. Second sample current waveform result for the third scenario of pulse burden circuit

Figure 17 shows the fourth scenario of pulse burden circuit. In this circuit, it was pure 2.7 $\mathrm{M} \Omega$ resistive burden that series with $300 \mathrm{k} \Omega$ resistor that shunted by $15 \times 10 \mu \mathrm{F}$ in parallel.

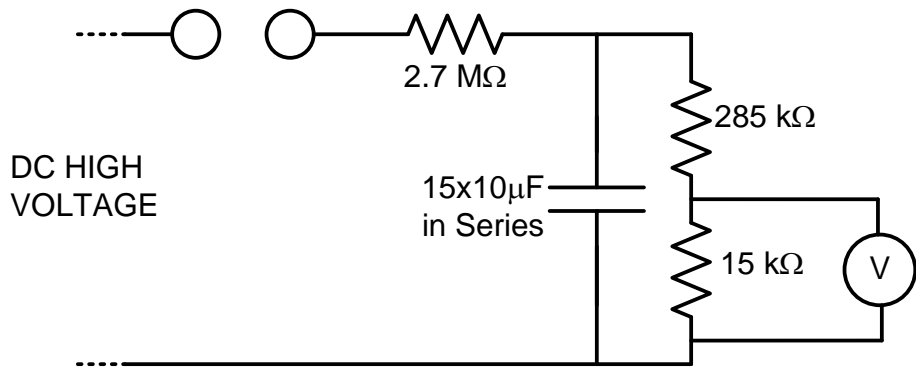

Figure 17. Fourth scenario of pulse burden as long capacitive-resistive circuit

Figure 18 shows the first sample current waveform of measurement result for the fourth scenario of pulse burden circuit. Figure 18(a) shows the first single waveform of discharge pulse. In this waveform, the discharge pulse was occurred in time of around $1 \mu$ s, and the specific discharge wave would cease in time of around $2 \mu \mathrm{s}$. Figure 18(b) shows the multiple waveform of discharge pulse. In this waveform, the discharge pulses were occurred in time of $0.9,21.1,39.3,56.1,72.3,89.9,104.3$ and $118.3 \mu \mathrm{s}$, after the first pulse. Nevertheless, almost pulses were negative values. The average different time among pulses was $16.8 \mu$ s. Figure $18(\mathrm{c})$ is the short range of frequency response. The magnitude would increase locally in frequency of 
$26855 \mathrm{~Hz}$, and Figure 18(d) is the long range one, where the current magnitudes remained relatively high.

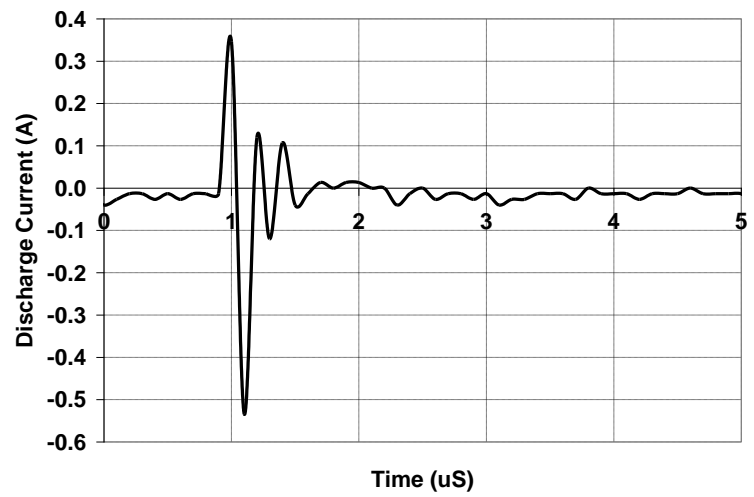

(a) First single waveform

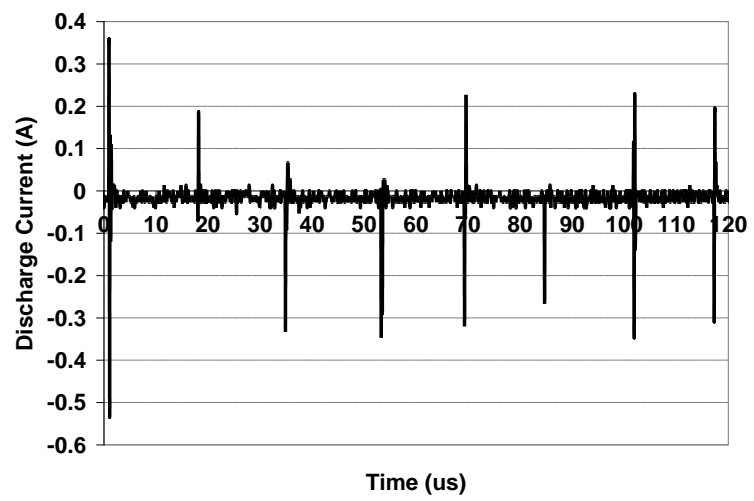

(b) Multiple waveform

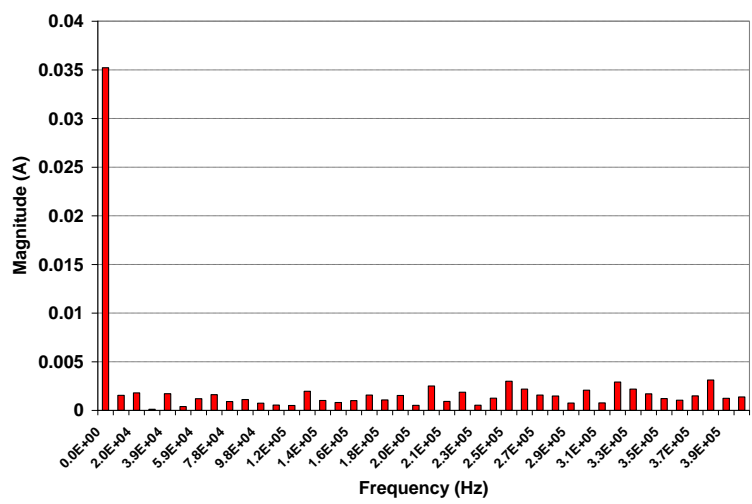

(c) Short range of frequency response 
Waluyo, et al.

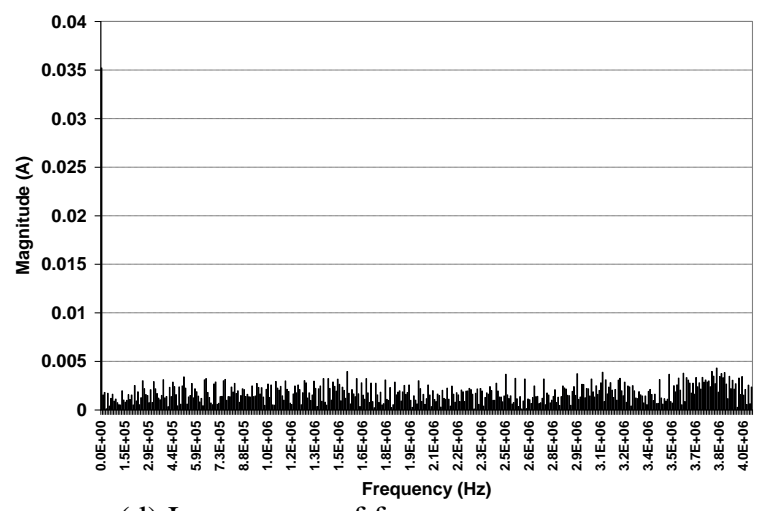

(d) Long range of frequency response

Figure 18. First sample current waveform result for the fourth scenario of pulse burden circuit

Figure 19 shows the second sample current waveform of measurement result for the fourth scenario of pulse burden circuit. Figure 19(a) is the first single waveform of discharge pulse. In this waveform, the discharge pulse was occurred in time of around $0.75 \mu \mathrm{s}$, and the specific discharge wave would cease in time of around $1.5 \mu$ s. Figure 19(b) is the multiple waveform of discharge pulse. In this waveform, the discharge pulses were occurred in time of $0.9,20.7,40.5$, $59.5,74.9,89.7,105.3$ and $118.3 \mu \mathrm{s}$, after the first pulse. Nevertheless, almost pulses were negative values. The average different time among pulses was $16.8 \mu$ s. Figure 19(c) is the short range of frequency response. The magnitude would increase locally in frequency of $48828 \mathrm{~Hz}$, and Figure 19(d) is the long range one, where the current magnitudes remained relatively high.

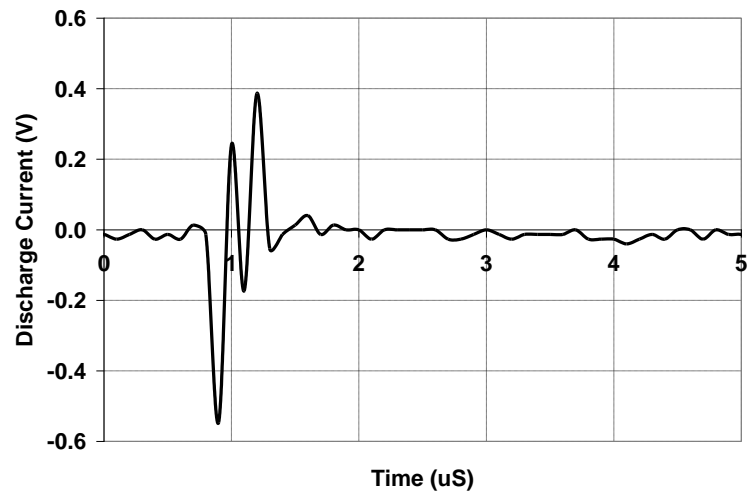

(a) First single waveform

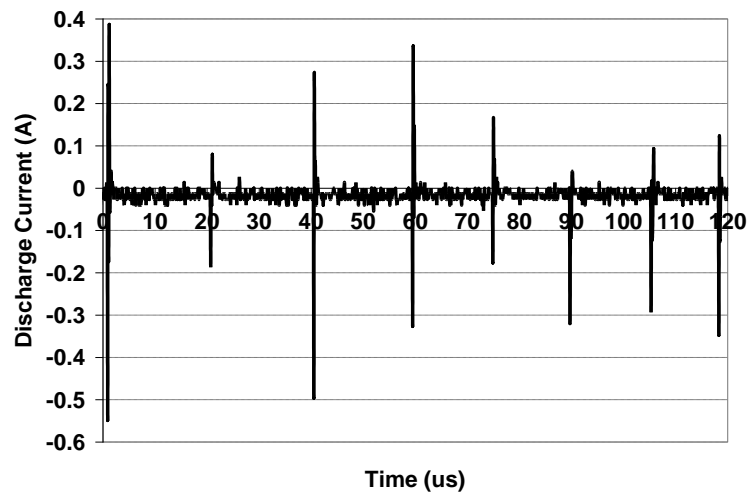

(b) Multiple waveform 


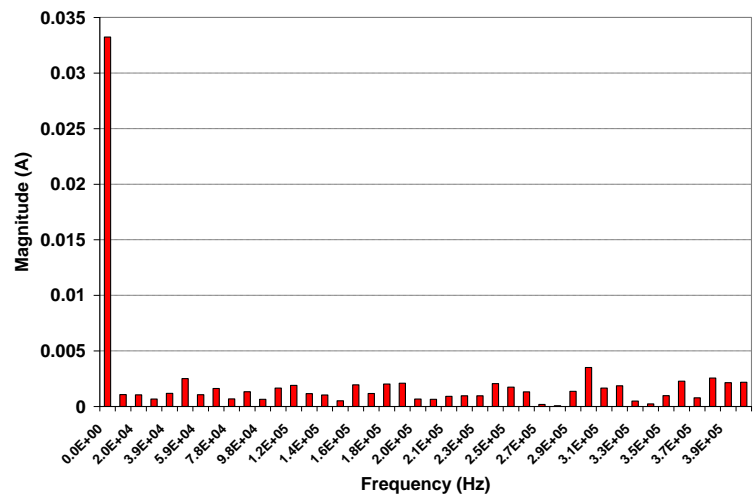

(c) Short range of frequency response

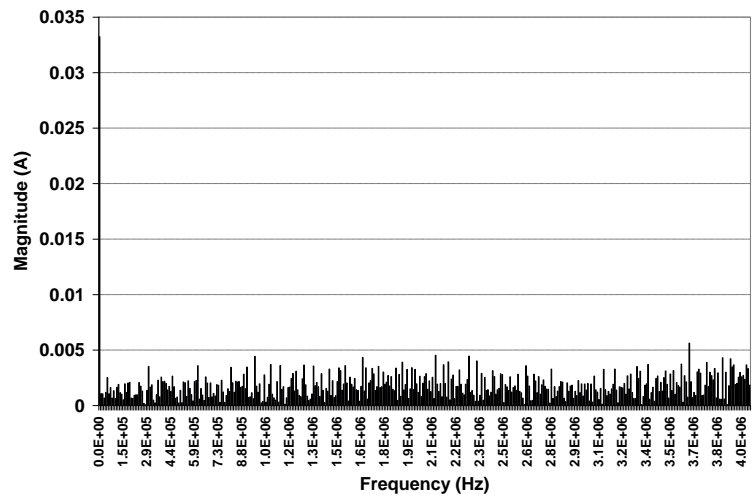

(d) Long range of frequency response

Figure 19. Second sample current waveform result for the fourth scenario of pulse burden circuit

Table 1. Time of discharge and frequency response due to some circuit scenarios

\begin{tabular}{|c|c|c|c|c|}
\hline Scenario & $\begin{array}{l}\text { Impulse } \\
\text { burdens }\end{array}$ & $\begin{array}{c}\text { Times of discharge } \\
(\mu \mathrm{s})\end{array}$ & $\begin{array}{c}\text { Averages different } \\
\text { time of discharge }(\mu \mathrm{s})\end{array}$ & $\begin{array}{c}\text { Frequencies of } \\
\text { increasing magnitude } \\
\text { locally }(\mathrm{Hz})\end{array}$ \\
\hline \multirow[t]{2}{*}{1} & \multirow{2}{*}{$\begin{array}{l}\text { Short pure } \\
\text { resistive } \\
\text { circuit }\end{array}$} & $\begin{array}{c}31,51,67,86,101, \\
116\end{array}$ & 17 & $34180,43945,61035$ \\
\hline & & $26,45,66,83,98,111$ & 17 & $31738,48828,61035$ \\
\hline \multirow{2}{*}{2} & \multirow{2}{*}{$\begin{array}{l}\text { Long pure } \\
\text { resistive } \\
\text { circuit }\end{array}$} & $30,54,74,92,111$ & 20 & $26855,36621,53711$ \\
\hline & & $27.5,53,73,94,112$ & 22.24 & $26855,36621,46387$ \\
\hline \multirow[t]{2}{*}{3} & \multirow{2}{*}{$\begin{array}{l}\text { Short } \\
\text { resistive- } \\
\text { capacitive } \\
\text { circuit }\end{array}$} & $27.5,53,73,94,112$ & 22.24 & 61035 \\
\hline & & $21,43.6,61,81,107.6$ & 21.32 & 36621,48828 \\
\hline \multirow{2}{*}{4} & \multirow{2}{*}{$\begin{array}{l}\text { Short } \\
\text { resistive- } \\
\text { capacitive } \\
\text { circuit }\end{array}$} & $\begin{array}{c}0.9,21.1,39.3,56.1 \\
72.3,89.9,104.3 \\
118.3\end{array}$ & 16.8 & 26855 \\
\hline & & $\begin{array}{c}0.9,20.7,40.5,59.5 \\
74.9,89.7,105.3 \\
118.3\end{array}$ & 16.8 & 48828 \\
\hline
\end{tabular}

Based on some discharge waveforms of testing results, it is observed that the waveforms with the pure resistive burdens would trend to be symmetrical to almost on positive parts. On 
the other hand, the waveforms with the resistive and capacitive dominated burdens would be shorter, i.e. around $16.8 \mu$ s, than those resistive dominated burdens, i.e. around $17 \mu \mathrm{s}-22.24$ $\mu$ s in average. The wave frequency response of discharge on the capacitive dominated burdens would be more declivous than those on the resistive dominated burdens. The latter characteristics are indicated by the specific capacitive dominated property. Table 1 lists the tabulation of the time of discharge and frequency response due to some circuit scenarios. Based on the table, the dominated capacitive existence made the repetitive discharge would be shorter than those the dominated resistive existence. The capacitive property that store charge was expected as cause the latter characteristics.

\section{Conclusion}

Almost all of the first discharge were occurred in around from $1 \mu$ s to $2 \mu \mathrm{s}$. The waveforms with the pure resistive burdens would trend to be symmetrical to almost on positive parts. On the other hand, the waveforms with the resistive and capacitive dominated burdens would be shorter than those resistive dominated burdens. The wave frequency response of discharge on the capacitive dominated burdens would more declivous than those on the resistive dominated burdens. The latter characteristics are indicated by the specific capacitive dominated property. The dominated capacitive existence made the repetitive discharge would be shorter than those the dominated resistive existence. The capacitive property that store charge was expected as cause the latter characteristics.

\section{Acknowledgments}

We would like to express the deepest appreciation to The Institute for Research and Community Service, National Institute of Technology (ITENAS), which has supported the funding in the research.

\section{References}

[1]. Wadhwa,C.L., "High Voltage Engineering (Second Edition)", New Age International (P) Limited, Publishers, 2007, ISBN: 978-81-224-2323-5, pp.81-104.

[2]. Lucas, J.R., "High Voltage Engineering, Department of Electrical Engineering", University of Moratuwa, Sri Lanka, Revised Edition, 2001, pp.8-147.

[3]. Kuffel, E., Zaengle, W.S., Kuffel, J., "High Voltage Engineering Fundamentals", Newnes, Butterworth-Heinemann, 2000, ISBN: 7506-3634-3, pp.48-75.

[4]. Naidu, MS., Kamaraju, V., "High Voltage Engineering", Second Edition, McGraw-Hill, 1996, ISBN: 1996, ISBN: 0-07-462286-2, pp.129-150.

[5]. Edirisinghe, M., "Nonlinear Load and RLC Pulse Shaping Surge Generator Models in Simulation Environment", International Letters of Chemistry, Physics and Astronomy, Vol. 36(2014), SciPress Ltd, Switzerland, pp.334-347.

[6]. Schon, K., "High Impulse Voltage and Current Measurement Techniques", Springer International Publishing, Switzerland 2013, ISBN: 978-3-319-00377-1, pp.5-30.

[7]. Holtzhausen JP., Vosloo, WL., "High Voltage Engineering", Practice and Theory, Draft Version of Book, ISBN: 978-0-620-3767-7, pp.86-91.

[8]. Ramleth Sheeba, Madhavan Jayaraju, Thangal Kunju Nediyazhikam Shanavas, "Simulation of Impulse Voltage Generator and Impulse Testing of Insulator using MATLAB Simulink", ISSN 1 746-7233, World Journal of Modelling and Simulation, England, UK, Vol. 8 (2012) No. 4, pp. 302-309.

[9]. Steven E. Meiners, J. R. Boston, H. K. Kim, R. G. Colclaser, "An Impulse Generator Simulation Circuit", Thesis at Electrical Engineering, University of Pittsburgh, November 25, 2002.

[10]. Y Choyal, Lalit Gupta, Preeti Vyas, Prasad Deshpande, Anamika Chaturvedi, K C Mittal dan K P Maheshwari, "Development of a 300-kV Marx generator and its application to drive a relativistic electron beam”, Sadhana Vol. 30, Part 6, December 2005, pp. 757-764, India. 
[11]. Muhammad Saufi Kamarudin, Erwan Sulaiman, Md Zarafi Ahmad, Shamsul Aizam Zulkifli and Ainul Faiza Othman, "Impulse Generator and Lightning Characteristics Simulation using Orcad PSpice Software", Proceedings of EnCon2008, 2nd Engineering Conference on Sustainable Engineering Infrastructures Development \& Management, December 18 -19, 2008, Kuching, Sarawak, Malaysia.

[12]. Takayoshi Nakata, Yoshiyuki Ishihara dan Tadataka Moriyasu, "Calculation of Circuit Constants for Impulse Voltage Generator by Means of Computer", Memoirs of The School of Engineering, Okayama University, Vol. 1, No.1, March, 1966.

[13]. Jari Hallstro, "A Calculable Impulse Voltage Calibrator, Acta Polytechnica Scandinavia", Electrical Engineering Series No. 109, Espoo 2002, 107, Finnish Academies of Technology, Finland, 2002, ISBN: 951-22-6174-X, pp.60-70.

[14]. Yeong-Jer Chen, B.S.E.E., Andreas Neuber, John Mankowski, "Compact Repetitive Marx Generator and HPM Generation with the Vircator", Electrical Engineering Graduate, Faculty of Texas Tech University, December, 2005.

[15]. A.A. Hueiit, E. Bautista, L.J. Villegast Anij M. Villagiian, "High voltage pulse generators and spark gap for gaseous discharge control", Instrumentación Revista Mexicana de Física 41, No. 3,1995, pp.08-.18.

[16]. Ju-Hong Eom, Sung-Chul Cho $\dagger$ and Tae-Hyung Lee*, "Parameters Optimization of Impulse Generator Circuit for Generating First Short Stroke Lightning Current Waveform", J Electr Eng Technol Vol. 9, No. 1: 286-292, 2014.

[17]. Zhu, Y., Zuegel, J.D., Marciante, J.R., Wu, H., "Distributed Waveform Generator: A New Circuit Technique for Ultra-Wideband Pulse Generation, Shaping and Modulation", IEEE Journal of Solid-State Circuits, Vol. 44, No. 3, March 2009, pp.808-823.

[18]. Waluyo, Syahrial, Sigit Nugraha, Yudhi Permana JR, "Miniature Prototype Design and Implementation of Modified Multiplier Circuit DC High Voltage Generator", International Journal of Electrical Engineering \& Technology (IJEET), International Association for Engineering and Management Education (IAEME), Volume 6, Issue 1, January (2015), pp. 01-12.

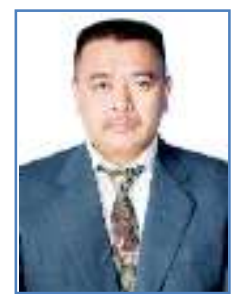

Waluyo was born in Magelang, Indonesia in 1969. He received B.Eng., M.Eng., and Doctor Degrees in electrical engineering from Bandung Insitute of Technology (ITB), Indonesia, in 1994, 2002 and 2010 respectively. Since 2003, he is a Lecturer at Department of Electrical Engineering, National Institute of Technology (Itenas) Bandung, Indonesia. His research interests include of high voltage phenomena. He received Best Lecturer in Kopertis IV in 2013.

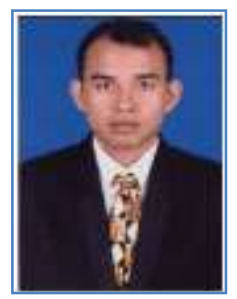

Syahrial was born in Lirik, Sumatera, Indonesia in 1969. He received B.Eng., Degree in electrical engineering from National Insitute of Technology (Itenas) Bandung, Indonesia, in 2000, and M.Eng. Degree in electrical engineering from Bandung Insitute of Technology (ITB), Indonesia, in 2004. Since 2005, he is a Lecturer at Department of Electrical Engineering, National Institute of Technology (Itenas) Bandung, Indonesia. His research interests include of electrical machines. 


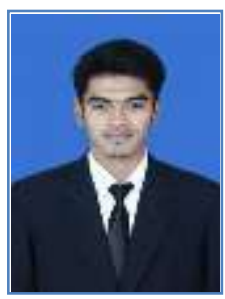

Sigit Nugraha was born in Subang, West Java, Indonesia. He is currently senior university student and doing final project at The Department of Electrical Engineering, National Institute of Technology (Itenas) Bandung, Indonesia.

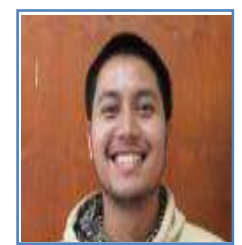

Yudhi Permana JR was born in Padang, West Sumatera, Indonesia. He is currently senior university student and doing final project at The Department of Electrical Engineering, National Institute of Technology (Itenas) Bandung, Indonesia. 